\title{
A Correlative Analysis of Modern Logistics Industry to Developing Economy Using the VAR Model: A Case of Pakistan
}

\author{
Salman Hanif $\mathbb{D D}^{1}$ Dong Mu $\mathbb{D}^{1},{ }^{1}$ Saranjam Baig $\mathbb{D}^{2},{ }^{2}$ and Khalid Mehmood Alam $\mathbb{D}^{1,3}$ \\ ${ }^{1}$ School of Economics and Management, Beijing Jiaotong University, No. 3 Shangyuancun, Haidian District, \\ Beijing 100044, China \\ ${ }^{2}$ College of Economics and Political Science, Sultan Qaboos University, Muscat 113, Oman \\ ${ }^{3}$ Center for Research on CPEC, Karakoram International University, Gilgit-Baltistan 15100, Pakistan \\ Correspondence should be addressed to Dong Mu; dmu@bjtu.edu.cn
}

Received 23 June 2020; Revised 5 November 2020; Accepted 18 November 2020; Published 7 December 2020

Academic Editor: Long Truong

Copyright (c) 2020 Salman Hanif et al. This is an open access article distributed under the Creative Commons Attribution License, which permits unrestricted use, distribution, and reproduction in any medium, provided the original work is properly cited.

\begin{abstract}
The modern logistics industry has opened new strategic perspectives in establishing its interrelation with economic growth. In recent years, understanding such an overlap has become a policy issue considering ever-increasing factors and their influence on this relation. Most existing studies have explored this interaction from a general perspective, or for developed countries. This paper explores time-series analysis of the dynamic variables and their inter-related influence in both the short and long run on the relationship between modern logistic industry and economic growth-a more specific perspective, particularly for developing countries. Accordingly, we exemplify our analysis by employing the vector autoregression (VAR) model to the most updated time series data of investment in the logistics industry and the economic growth of Pakistan from 1990 to 2018. The empirical findings endorse the previous studies' outcomes and recognize the importance of sustainable economic development concerning continuously improving the logistics industry. However, a unidirectional relation is observed that economic growth leads to developing the logistics industry-economic growth exerts a significant demand-pull effect on Pakistan's logistics. It implies that logistic industrial development is comparatively quicker in the geographical areas where economic growth is higher than those areas where economic growth is low. To conclude this study's findings, logistics industry reforms should prioritize the selected geographical areas in improving the economy that would lead to the modern logistics industry's development. As the model adopts Pakistan's context, the overall statistical analysis can be generalized to other developing economies. These results would be of particular interest to strategy makers working in developing countries and help them design and develop modern transportation and logistics, coupled with interlinked technological factors, which would attract investment in the logistics industry for sustainable economic development.
\end{abstract}

\section{Introduction}

tThe logistics industry consists of efficiently organizing, executing, and controlling the movement of products, services, and information from source to consumer. It is a component of the value-chain process [1] that integrates the service with equipment [2]. This industry has become an entity involving complex systems and management technology in facing off globalization and modern social demands-a modern logistics industry. Thus, the modern logistics industry and its association with economic development have gradually revealed ongoing imperative strategic and competitive positions.
The growth of the modern logistics industry concerning economic development can be observed in multiple aspects. First, the logistics industry acts as a network that amplifies each of its functions to promote the entire network's revenues and customizes services to shrink the performance risks [3]. Second, a growing logistics industry facilitates the expansion of improved tertiary industrial structure by coordinating cross-functional tasks, thus achieving the economy of scale and division of labour [4]. Third, the logistics industry has incorporated e-business applications that accelerate global competition and economic growth $[5,6]$. Fourth, the modern logistics industry has broadened its 
scope from transportation and warehousing to an integrated system such as transportation, inventory management, warehouse management, material handling, packaging, and supply chain management [7]. Finally, the country's location is the most critical standpoint. For instance, the demand for a more customized situation in exploring the interrelationship between logistics industry development and economic growth can influence the four aforementioned aspects [8]. These aspects drive a need for customized analysis of the ever-evolving logistics industry to the economy as required by a regional and social perspective. However, related studies viewed this relationship differently.

Many empirical studies have explored the relationship between the logistics industry and the economy. Some researchers observed logistics in exploring similar relationships [9-11]. In contrast, the other empiricists investigated the impact of transport and logistics on economic growth [12-14]. Besides, few scholars have also focused on logistics infrastructure and its positive relationship with economic growth [15-17]. Likewise, some researchers have also included geographical features in exploring the relationship between the logistics industry and economic growth [18-24].

Existing literature has numerous shortcomings. First, existing studies mainly focus on transport and logistics infrastructure and have ignored most logistics industry components - the modern logistics industry. Second, existing studies have mainly focused on developed economies [25]. Particularly, the geostrategic features of developing countries have not been fully explored. Therefore, exploring the modern logistics industry's scope and aims and its relation to a country's economic policy seems imperative. Finally, the association between logistics infrastructure and economic growth is dynamic because the logistics industry's growth is followed by economic development and vice versa. Accordingly, a quantitative analysis is required to explore such relationships that facilitate visual and convincing results in understanding the impact of relationship to the researchers and practitioners [2]. Subsequently, many statistical models have been employed to analyze two-dimensional relationships, such as regression analysis, variance analysis, and principal component analysis. Nevertheless, these techniques have a very high requisite for sample size and sample distribution. As a result, a large sample size is required to study the population to follow certain distinctive probability distributions. Given these points, existing literature has a substantial research gap concerning the correlation between the modern logistics industry and the national economy, particularly from developing countries' aspect.

This study focuses on the points mentioned above while analyzing the modern logistics industry's relationship with the economy. Accordingly, we employed an econometric model to investigate short- and long-run relationships between the modern logistics industry and economic growth. Moreover, this relationship is explored from a quantitative perspective to achieve a visual and convincing impact [2]. Accordingly, two indicators are examined: gross domestic product (GDP) as the economic indicator index and gross capital formation (GCF) as the investment indicator in the logistics industry's fixed assets. The updated data of these variables are taken from the State Bank of Pakistan and Pakistan Bureau of Statistics from the period of 1990 to 2018. Methodologically, the vector autoregressive (VAR) model is used to examine empirically the relationship of investment in the modern logistics industry and economic growth that requires normalizing the two parameters. First, the unit root test is applied to determine the degree of stability. Second, cointegration analysis is applied to determine the long-run relationship between nonstationary time-series variables. It requires the same degree of variables, and the cointegration indicates that these variables move together, depicting a long- and short-run causal relationship. Third, the correlation is also examined between these two variables. Fourth, we applied the VAR model, and finally, a Granger causality test is employed to examine the cointegration. This study used the statistical software EViews 11 package program for the econometric analysis.

The data, used to examine the relationship between the modern logistics industry and economic growth, were taken from Pakistan for the following reasons. First, Pakistan's geography holds an essential global position in strategic terms and acts as a bridge between Asia, Africa, the Middle East, and the Arabian Sea. Second, according to the Pakistan Bureau of Statistics, Pakistan's logistics and transport sector contribute $22.3 \%$ of the service sector, while it takes part in $10 \%$ of the nation's GDP. Moreover, it accounts for around $6 \%$ of the nation's total employment. On the other hand, Pakistan ranked 122 out of 163 countries in the World Bank's logistics performance index (LPI). However, the logistics performance score is below 2.5 (1 (low) to 5 (high)) for 2018-19, as shown in Figure 1 and Figure 2, respectively [26]. This poor performance in the logistics industry can be attributed to the inefficient services in customs clearance, tracing, tracking, and meeting the timelines throughout the country. Nevertheless, Pakistan is also trying to meet the overwhelming logistics demand while simultaneously eliminating its colonial infrastructure. Finally, a lack of longterm government planning is one of the bottlenecks in improving a logistic value-chain. Therefore, it would be interesting to investigate whether Pakistan's logistics infrastructure can encounter economic development demand. Given the reasons mentioned above and our limited knowledge, no study currently examines the relationship between the logistics industry development and economic growth for a developing country like Pakistan with such a large structure. We believe the concepts and the models presented to analyze the relationship between modern logistics development and economic growth can help decision-makers of developing countries facilitate the strategic formulation and policymaking and minimize unfavorable future events or conditions.

The remaining structure of the paper is outlined as per the following. Section 2 illustrates the review of the literature. Section 3 describes the data and methodology used. 


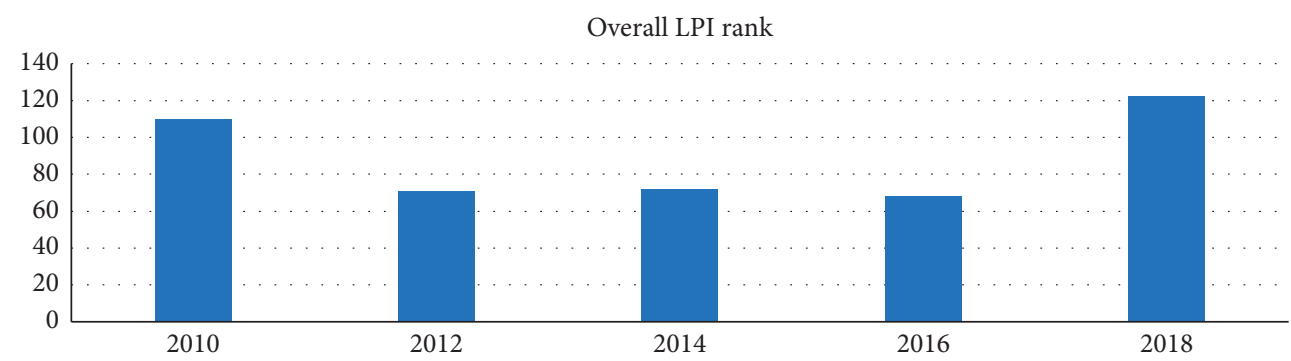

Figure 1: Logistic performance index (LPI) rank of Pakistan from 2010 to 2018 . The $x$-axis shows the years, and the $y$-axis shows the LPI rank (source: https://lpi.worldbank.org/international/scorecard/radar/8/C/PAK/2018).

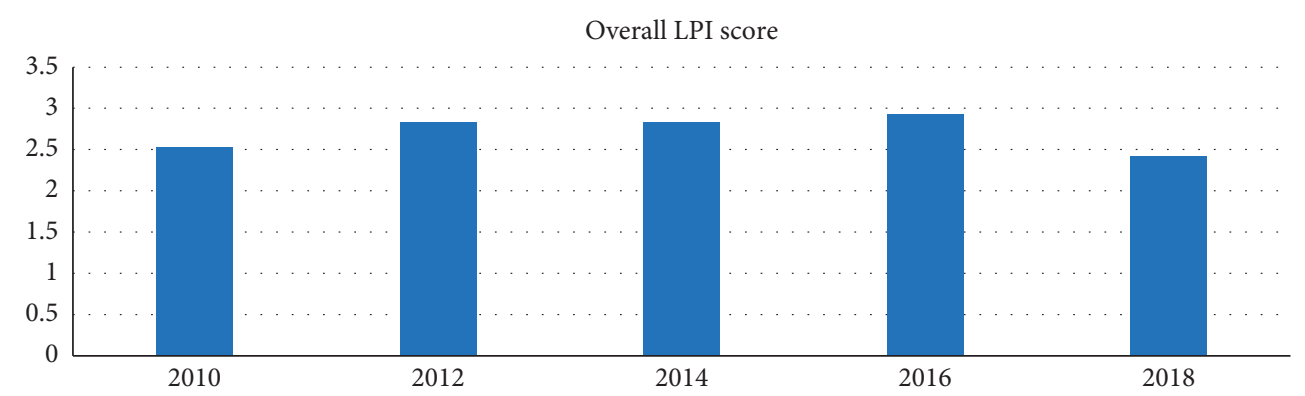

Figure 2: Logistic performance index score (1 (low) to 5 (high)) of Pakistan from 2010 to 2018. The $x$-axis shows the years, and the $y$-axis shows the LPI score (source: https://lpi.worldbank.org/international/scorecard/radar/8/C/PAK/2018).

Section 4 explains the empirical results and discussion, while Section 5 consists of a conclusion and policy recommendation.

\section{Review of the Literature}

Existing literature has examined the logistics industry's relations to economic growth in developed and developing countries. This section describes such relations from three different contexts: general, developing countries, and Pakistan.

In general, previous studies have explored such relationships from a multidimensional perspective. In some studies, logistics is viewed as a prime factor while observing the multidimensional relationship of logistics infrastructure to economic growth $[10,11]$. For instance, efficient logistics services facilitate the production process and influence productivity that ultimately increases the supply-demand of products [27], lowers the production overheads and operational cost [28], and stimulates industry innovation and technological spillover [29]. Here, the main objective was to identify the influential factors [30-33] and explain an interrelation between logistics and economy [34-37]. In contrast, other studies have investigated the impact of transport and logistics in investigating similar relationships [12-14]. For example, researchers in those studies analyzed multiple associations, including the interrelationship between traffic turnover volume, freight volume, and economic growth $[38,39]$; relating the port capacity to the total value of import and export; linking external trade to economic growth $[13,16,24]$; and associating logistics services to economic activity [40]. Likewise, other studies focused on logistics infrastructure in exploring its positive relationship with economic growth $[15,17,41]$ and mostly applied quantitative models to study this correlation $[42,43]$. While examining the direction of correlation, Mohmand et al. [44] suggest a long-run unidirectional causality from economic development to infrastructure investment, and other researchers suggest that logistics infrastructure, including ports, roads, and trade, facilitate economic growth [30, 32, 45]. Moreover, the geographical features were also studied in exploring similar relationships [18-24]. For instance, logistics industry's development corresponds to regional economic needs [46] and the evaluation system of regional logistics adaptability corresponds to the regional economy [18]. Similarly, Mohmand et al. [44] argue that from economic growth to transportation infrastructure, the developed provinces and underdeveloped provinces show a bidirectional and unidirectional causality, respectively. This is because the regional economic integration may involve multiple logistics variables (freight, freight turnover) $[19,47]$.

In recent years, developing countries have been engaged in fierce competition, attempting to lift their economy by upgrading logistics' poor states [10, 48, 49]. Furthermore, while discussing the logistics' channel to growth, Khan et al. [50] argue that developing countries are often stuck in a low productivity vicious circle. Kuzu and Onder [19] studied the long-run interrelation of the logistics sector to economic growth in Turkey. Reza [22] investigated a similar relationship in Indonesia and found that economic growth shows a significant demand-pull effect on logistics. Moreover, Bose and Haque [51] studied the role of investment in transportation and economic growth for many developing 
countries and observed bilateral causal relationships between those variables. Khan et al. [52] examined the impact of green supply chain practices (GSCPs) on competitive advantage, economic, environmental, and organizational performance under the influence of internal environment management and green information systems. Khan et al. [53] examined the potential relationship between public health expenditures, logistics performance indices, renewable energy, and ecological sustainability in the Association of Southeast Asian Nations member countries. Khan et al. [54] investigated the relationship between green logistics indices, economic, environmental, and social factors in the perspective of Asian emerging economies. Khan et al. [50] examined the association between green logistics operations, social, environmental, and economic indicators of SAARC (South Asian Association for Regional Cooperation) countries. One study examined the influence of logistics competence in international trade with special reference to Sri Lanka [55]. Overall, these studies show that economic growth is conditioned on the logistics performance level in the developing countries [10, 48, 49].

In developing countries like Pakistan, logistics infrastructure is crucial in reaping productivity from the industrial sector [56]. It shows the direct and indirect effects of transportation on Pakistan's economic growth [44, 57]. However, some studies have empirically verified the positive impact of flexibility and collaboration on logistic efficiency in Pakistan [58] and transport cost and travel time on trade for current routes and modern transportation [57]. Similarly, Rehman et al. [59] explored trade and transport efficiency to ascertain trade and economic development by transport infrastructure. No doubt, efficient and safe air, rail, road, and sea transport play a notable role in a country's economic and societal self-development. Accordingly, the role of transport becomes pivotal in entire regions' collegial prosperity and socioeconomic capabilities [60]. Even the existing studies provide a useful insight into the impact of the logistic industry and economic growth across various countries; a few studies are found to be reliable and robust in examining a similar perspective on Pakistan $[44,56,61]$. In particular, the logistics industry has not been fully explored in connection with developing economies like Pakistan, which holds an essential place in the world in terms of its strategic location and acts as a bridge between Asia, Africa, and the Middle East in the Arabian Sea.

\section{Research Methodology}

The current study's empirical analysis involves employing the VAR model to examine the relationship between the logistics industry's development and economic growth. The VAR model, commonly used in econometrics, was first proposed by Christopher Sims in 1980 [62]. Generally, this model is used to forecast inter-related time-series systems and analyze the dynamic impact of random disturbances on those systems of variables. As the main feature, the VAR approach bypasses the structural modeling by treating each variable as endogenous, thereby acting as a function of lagged values of all endogenous system variables. Moreover, each variable in this model is a linear function of past lags of itself and past lags of the other variables, where every variable has one equation as a dependent variable. A conventional VAR model of n-vector time-series variables, with $k$ lags, is written as

$$
v_{t}=a_{1} v_{t-1}+a_{2} v_{t-2}+\ldots+a_{p} v_{t-p}+b x_{t}+\mu_{t}
$$

where $v_{t}$ is the endogenous vector, $x_{t}$ is the exogenous vector, $\mu_{t}$ is the disturbance vector, and $a_{1} \ldots a_{p}$ and $b$ is the estimated coefficient matrix vector.

As the VAR model uses time-series data in its analysis, accordingly, the issue of heteroscedasticity was neutralized by taking the natural logarithm of the variables [63, 64]. Afterwards, GDP and GCF, both variables were subjected to a stationary test. Then, the cointegration test was conducted to validate the variation in the original sequence. Furthermore, the VAR model and a time-series causality test were conducted, respectively $[22,65]$. We used the statistical software Eviews-11 package program to perform the aforementioned econometric analysis. The results and their interpretation are presented in the Empirical Results and Discussion section of this paper.

3.1. Data and Variables. The modern logistics industry represents the transportation business but covers many components such as warehousing, inventory handling, distribution planning, packaging, loading, unloading, carrying, and value-added logistics services. Accordingly, one of the main challenges in the methodology section was selecting the logistics industry's representative index and collecting the corresponding data. Consequently, this analysis has used transportation, storage, and postal services to indicate the logistics industry. Moreover, keeping in view the data availability constraints, the gross capital formation was taken as an indicator of investment in the logistics industry's fixed assets and is denoted by GCF. Furthermore, the GDP was selected as a measure of economic growth. The time-series data of these representatives' indexes were taken from the Pakistan Bureau of Statistics and World Bank, world development indicator [26], the most authentic and reliable data sources, from 1990 to 2018 . Table 1 lists the data of the selected representative index and their natural log. However, the graphical representation of the same data is expressed in Figures 3 and 4.

\section{Empirical Results and Discussion}

This section describes the results and discussion of quantitative analysis using various statistical tools, including stability test, cointegration test, correlation, applied VAR model, and Granger causality test.

4.1. Stability Test. The stability test is also termed as the stationary time-series test. It represents the mean of timeseries data to determine whether the variance and autocovariance are "stable" or "unstable." The data are stable when the time-series data show a stable mean, variance, and autocovariance and vice versa. Moreover, the natural log is 
TABLE 1: The data of gross domestic product (GDP) and investment in the logistics industry (GCF) of Pakistan is listed from 1990 to 2018.

\begin{tabular}{ccccc}
\hline Year & GDP (million) & GCF (million) & Log GDP & Log GCF \\
\hline 1990 & 4120871 & 928919 & 29.0471 & 27.5573 \\
1991 & 4329451 & 956915 & 29.0965 & 27.587 \\
1992 & 4663074 & 1056303 & 29.1707 & 27.6858 \\
1993 & 4745040 & 1097983 & 29.1881 & 27.7245 \\
1994 & 4922381 & 1089582 & 29.2248 & 27.7168 \\
1995 & 5166660 & 1131262 & 29.2733 & 27.7544 \\
1996 & 5417066 & 1195090 & 29.3206 & 27.8092 \\
1997 & 5472017 & 1151903 & 29.3307 & 27.7724 \\
1998 & 5611566 & 1187003 & 29.3559 & 27.8025 \\
1999 & 5816957 & 1077906 & 29.3918 & 27.706 \\
2000 & 6064764 & 1133114 & 29.4335 & 27.756 \\
2001 & 6184997 & 1181640 & 29.4532 & 27.7979 \\
2002 & 6384428 & 1178697 & 29.4849 & 27.7954 \\
2003 & 6693838 & 1253473 & 29.5322 & 27.8569 \\
2004 & 7187078 & 1188684 & 29.6033 & 27.8039 \\
2005 & 7738134 & 1340433 & 29.6772 & 27.924 \\
2006 & 8216160 & 1588348 & 29.7371 & 28.0937 \\
2007 & 8613232 & 1629607 & 29.7843 & 28.1194 \\
2008 & 8759778 & 1700342 & 29.8012 & 28.1619 \\
2009 & 9007825 & 1626948 & 29.8291 & 28.1177 \\
2010 & 9152553 & 1520646 & 29.8451 & 28.0502 \\
2011 & 9404102 & 1418781 & 29.8722 & 27.9808 \\
2012 & 9733907 & 1454831 & 29.9066 & 28.0059 \\
2013 & 10161854 & 1495238 & 29.9497 & 28.0333 \\
2014 & 10636891 & 1536447 & 29.9954 & 28.0605 \\
2015 & 11140138 & 1760001 & 30.0416 & 28.1963 \\
2016 & 11755824 & 1887998 & 30.0954 & 28.2665 \\
2017 & 12408775 & 2073722 & 30.1494 & 28.3604 \\
2018 & 13132237 & 2218301 & 30.2061 & 28.4278 \\
\hline & & &
\end{tabular}

The monetary figure of millions represents Pakistani rupees.

also taken for GDP and GCF to reduce the data volatility as $\mathrm{LGDP}=\log (\mathrm{GDP})$ and LGCF $=\log (\mathrm{GCF})$. Accordingly, we applied the augmented Dickey-Fuller (ADF) test, one of the variants of stability (stationarity, unit root) test [66]. Table 2 shows the results of the stability test.

In this table, ADF values of LGDP and LGCF are -1.0698 and 0.055 , respectively. Here, both ADF values are higher than the critical value at a 5\% confidence level. It implies that the logistics industry and economic growth in Pakistan are not smooth and show a nonstationary nature sequence from 1990 to 2018. These results are in agreement with the previous findings $[10,19,22,55]$. Later, the first-order differential of LGDP and LGCF was taken, which shows that the DLGDP value is -3.1356 and DLGCF is -4.0258 , i.e., both values are less than the critical value and under the 5\% significance level. Therefore, these two time-series values are stable after the first difference stationary test. These results endorse the previous findings $[10,19,22,55]$.

The ADF test shows that the LGCF value is unstable or has a unit root at the significance level 5\% and 10\% for both values, while its value is stable after taking first difference DLGCF on the 5\% level of significance. Moreover, the LGDP value is also unstable or has a unit root at both 5\% and $10 \%$ levels of significance, while its value is stable after taking the first difference DLGDP on a 5\% level of significance.
4.2. Cointegration Test. The cointegration test explores the long-term stable relationship between the two variables-in our case, the logistics industry and economic growth. Granger [67] and Engle and Granger [68] introduced the concept of cointegration. It is a useful statistical tool in testing long-run equilibrium relationships between nonstationary time-series. If two series are individually nonstationary and their linear combination is stationary, they are referred to as cointegrated $[67,68]$, as shown in Table 3. Our results show that the trace test indicates 1 cointegrating equation at the 0.05 level, which denotes rejection of the hypothesis at the 0.05 level of significance.

4.2.1. Normalized Long-Run Coefficient. The Johansen-Juselius cointegration method can provide us the estimated long-run coefficients of the variables [69]. The normalized long-run coefficients using the model of two variables LGDP and LGCF are shown in Table 4. It implies that moving the coefficient to the left-hand side of the equation will change the estimate to positive, indicating a positive effect on LGDP. These two variables show significant positive values of long-run coefficients, which suggests that the investment in developing the logistics industry enhanced Pakistan's economic growth in the long run, ceteris-paribus.

4.3. Correlation. The strength of the relationship between two continuous variables is examined by using a statistical technique called correlation analysis and Sir Francis Galton (1877) introduced this concept. The correlation is measured between two quantitative variables $X$ and $Y$ to determine the degree of association or correlation between them [70]. A correlation between variables indicates that when one variable changes in value, the other variable tends to change its value in a specific direction. Understanding this relationship is useful to predict the value of one variable given the other variable. In our analysis, the result of this test shows a significant positive correlation between variables, LGDP, and LGCF, as shown in Table 5.

4.4. VAR Model. The VAR model is commonly used in econometrics and was proposed by Christopher Sims in 1980 [71]. The basic principle of the VAR model is that it generalizes the univariate autoregressive model (AR model) by allowing it to carry more than one evolving variable. All variables in the VAR model enter in the same way, while each variable has an equation explaining its evolution based on its own lagged values-the lagged values of the other model variables and an error term. In this model, each variable is a linear function of past lags of itself and past lags of the other variables. In the analysis, when the maximum value of lag is 1, the SC value (Schwartz criterion) arrives at a minimum (-7.792085). While at the same time, the AIC (Akaike information criterion) is -8.077557 . The simple mathematical expression of the VAR model is as follows: 


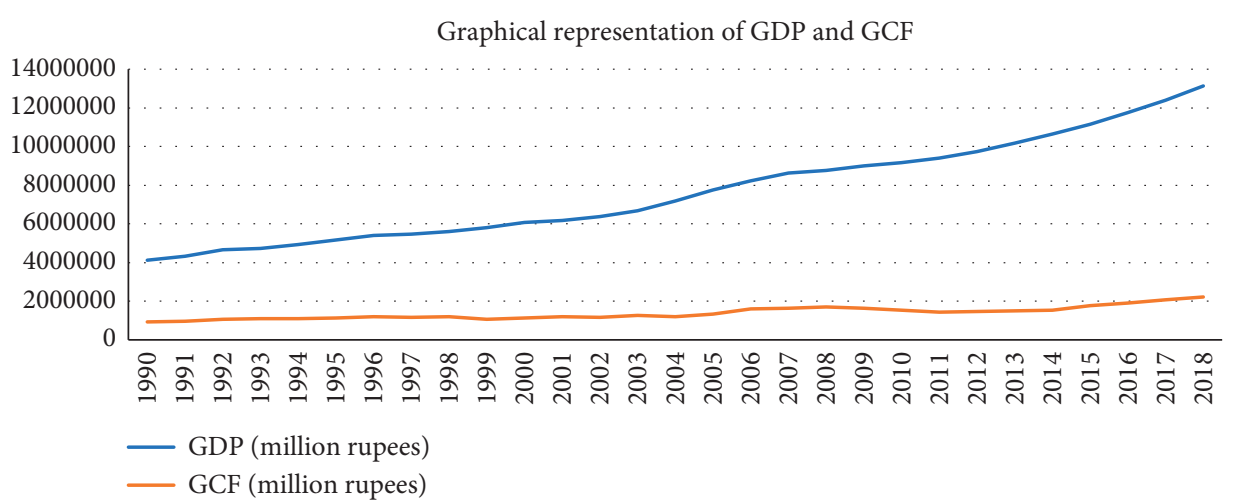

Figure 3: A graphical representation showing a comparison between GDP and GCF data from 1990 to 2018. The $X$-axis shows the number of years, while the $Y$-axis shows values in millions of Pakistani rupees.

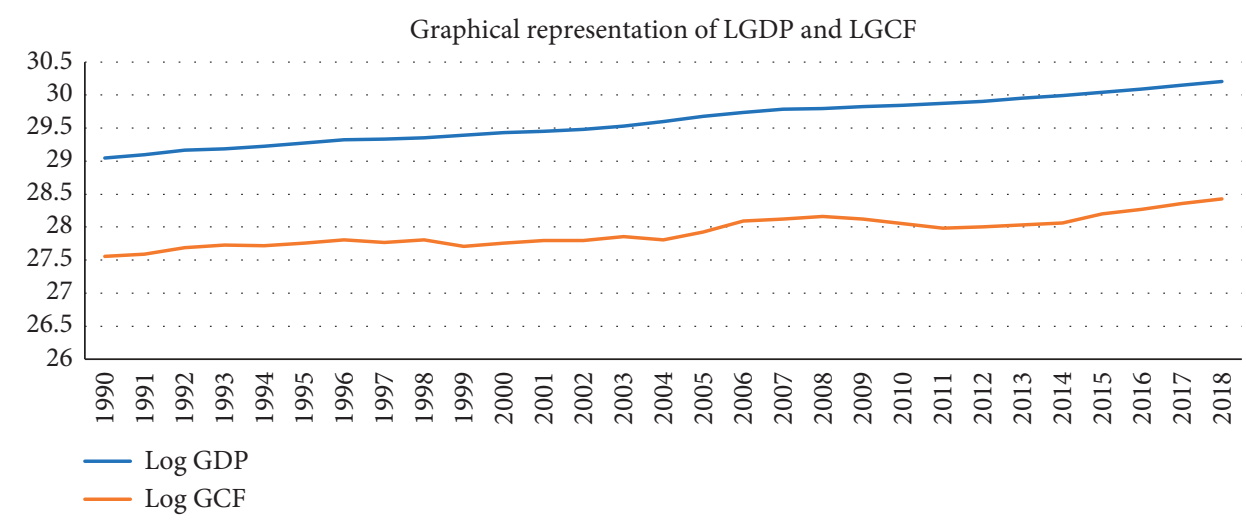

FIGURE 4: A graphical representation showing a comparison between LGDP and LGCF data from 1990 to 2018 . The X-axis shows the number of years, while the $Y$-axis shows values in millions of Pakistani rupees.

TABLE 2: Result of the ADF unit root test.

\begin{tabular}{lcccc}
\hline Variables & ADF test value & The $5 \%$ level of confidence & The 10\% level of confidence & Conclusion \\
\hline LGDP & -1.0698 & -2.998 & -2.6387 & Unstable \\
LGCF & 0.055 & -2.9718 & -2.6251 & Unstable \\
DLGDP & -3.1356 & -2.9762 & -2.6274 & Stable* $^{*}$ \\
DLGCF & -4.0258 & -2.9762 & -2.6274 & Stable* $^{*}$ \\
\hline
\end{tabular}

${ }^{*}$ The level of significance at $5 \%$.

TABLE 3: Johansen cointegration test.

\begin{tabular}{|c|c|c|c|c|}
\hline Hypothesized no. of CE(s) & Eigenvalue & Trace statistics & 0.05 critical value & Prob** \\
\hline None $^{*}$ & 0.531896 & 19.42142 & 15.49471 & 0.0121 \\
\hline At most 1 & 0.017635 & 0.444806 & 3.841465 & 0.5048 \\
\hline
\end{tabular}

The trace test indicates 1 cointegrating equation(s) at the 0.05 level. * Rejection of the hypothesis at the 0.05 level. ${ }^{* *}$ MacKinnon-Haug-Michelis $(1999) p$ values.

$$
\begin{aligned}
\ln (\mathrm{GDP})_{t}= & 0.7118+1.0517 \ln (\mathrm{GDP})_{t-1} \\
& -0.0788 \ln (\mathrm{GCF})_{t-1}, \\
\ln (\mathrm{GCF})_{t}= & 2.4840+0.2232 \ln (\mathrm{GDP})_{t-1} \\
& +0.6753 \ln (\mathrm{GCF})_{t-1} .
\end{aligned}
$$

Using the VAR model, it worthy to note that LGCF is positively affected by the previous period, but LGDP is negatively influenced by the previous period. However, LGDP is positively affected by its previous period, and it is also positively affected by the previous period of LGCF.

4.5. Granger Causality Test. Granger [72] causality is defined as follows: the variable $x_{i, t}$ causes $y_{i, t}$, if we are better able to predict $y_{i, t}$ using all available information, compared with the use of information without $x_{i, t}$, for each individual $i \in[1, N]$. 
TABLE 4: Normalized long-run coefficient of LGDP and LGCF.

\begin{tabular}{lc}
\hline 1 Cointegrating equation(s) & Log likelihood 126.7204 \\
\hline \multicolumn{2}{l}{ Normalized cointegrating coefficients (standard error in } \\
parentheses) & \\
LGDP & LGCF \\
1 & -1.629724 \\
& -0.08581 \\
\hline Adjustment coefficients (standard error in parentheses) \\
D(LGDP) & 0.09622 \\
& -0.0439 \\
D(LGCF) & 0.502336 \\
& -0.13257 \\
\hline
\end{tabular}

The negative sign indicates a positive effect on the second variable.

TABLe 5: Correlation between LGDP and LGCF.

\begin{tabular}{lcc}
\hline Variables & LGDP & LGCF \\
\hline LGDP & 1 & 0.947082 \\
LGCF & 0.947082 & 1 \\
\hline
\end{tabular}

We will assume that the Granger causality model is a linear one, and therefore, we will study a time-stationary VAR representation.

The Granger causality test suggests three kinds of results, i.e., unidirectional, bidirectional, and no causality. This test finds the lag order of one and two in order to check whether the one in index influences another in the following year or the following two years. Interpretation of this test explains that economic growth leads to the development of the logistics industry, or the investment logistics industry leads to economic growth. In a single lag, LGDP is found to Granger cause LGCF, at the $5 \%$ level of significance, whereas, in a double lag, LGDP is also found Granger cause LGCF, at the $5 \%$ level of significance. Finally, the other way around in both lag orders, LGCF does not Granger cause to LGDP. For instance, theoretically, these values are interpreted as if the variable $X$ helps to predict $Y$, then the regression of $Y$ is based on past values of $Y$. Similarly, if coupled with past values of $X$, then results can significantly enhance the explanatory power of regression. Therefore, $X$ is the Granger cause of $Y$, otherwise known as non-Granger reasons. The results of the Granger causality test are shown in Tables 6 and 7. The observation of these tables concludes that the time-series data constitute significant one-way causality from LGDP towards LGCF. It implies that economic growth is a significant demand-pull effect on logistics industry development. Our observation shows an agreement with previous studies $[10,19,22,55]$.

\section{Concluding Remarks}

5.1. Conclusion. This paper examines an empirical investigation of the causal relationship between modern logistics industry development and economic growth in both the short and long run, as influenced by dynamic variables and their inter-related impact. Using the most updated available data and advanced econometrics approach, we exemplified our analysis by employing the VAR model to time-series data from 1990 to 2018 related to investment in the logistics industry and economic growth of Pakistan. Findings revealed that the Granger causality test displays a one-sided causal relationship from economic growth to logistics industry development, which implies that the economic growth influences the logistic industrial development. In contrast, the logistics industry's development does not play a significant role in promoting economic growth. Empirical observation of this study suggests a need to identify the geographical regions, provinces, or cities on priority bases, where the economic development is relatively weaker, while the logistic industry and infrastructure are also at the developing phase.

Given we used GCF as a proxy in measuring the investments in the logistics infrastructure in Pakistan, results may reflect the proximate effects rather than actual effects. It remains a limitation to the study. However, it also opens avenues for further researchers to develop alternate measures for logistics infrastructure building on our research. Besides, another limitation is the availability of and access to data in Pakistan. We hope this gets better as the country embarks on digitalizing its operations. Our research also opens the debate for examining the questions related to other components within GCF.

5.2. Recommendations: The Pakistan Case. This study analyses the interaction between logistics industry development and economic growth to realize the harmonious relationship. The study observation indicates that Pakistan's economic growth derives a significant demand-pull effect on logistics industry development. Accordingly, some suggestions are proposed.

Currently, Pakistan is short of logistics network construction planning. First, the governments at all levels should upsurge capital investment in the logistics industry and positively educate, formulate, and implement numerous helpful policies. Meanwhile, respective authorities need to learn from the modern experience of developed countries. Second, government divisions should reinforce planning and guidance to pursue the modern logistics industry. Likewise, the tax collection structure of the logistics firms needs to be reformed and strengthened. Moreover, market order must be systematized to create a suitable environment for modern logistics industry development. Finally, related financial support policies should be synchronized to encourage and develop the logistics industry.

Another way of enhancing the logistics industry's efficiency and economic advantage is to lower the logistics cost by integrating enterprise information, government information, and social information with the distribution of logistics information resources. However, most logistics enterprises in Pakistan operate at a small scale or provide single logistic functions. These logistics enterprises provide two or more logistics functions and information services while excluding a third-party logistics business. Therefore, the government should encourage a logistics' public information platform to provide vital support to the modern logistics industry's development. Such platforms' primary 
TABLE 6: Granger causality test result.

\begin{tabular}{lccc}
\hline Null hypothesis & Obs. & F-statistic & Prob. \\
\hline LGCF does not Granger cause LGDP & 28 & 2.74284 & 0.1102 \\
LGDP does not Granger cause LGCF & & 4.30026 & 0.0486 \\
\hline
\end{tabular}

${ }^{*}$ The level of significance at $5 \%$.

TABLE 7: Granger causality test result.

\begin{tabular}{lccc}
\hline Null hypothesis & Obs. & F-statistic & Prob. \\
\hline LGCF does not Granger cause LGDP & 27 & 1.38563 & 0.2712 \\
LGDP does not Granger cause LGCF & & 9.81175 & $0.0009^{*}$ \\
\hline
\end{tabular}

${ }^{*}$ The level of significance at $5 \%$.

function is to share standardized and synchronized information by integrating social logistics information resources with all provinces' and cities' public information [73]. Moreover, these public information platforms would also facilitate accelerating the fourth-party logistics platform.

Data transmission efficiency significantly impacts the operation mode in the logistics industry in terms of speed and accuracy. For instance, many logistics companies still use the traditional mode of operation. One of the reasons is the reluctant to adopt high-tech in their operations like MIS, GPS systems, bar code identification systems, EDI technology, RFID technology, and other progressive logistics technology. The development of the modern logistics industry and the adoption of new technology would open untapped opportunities to induce skilled and professional talent equipped with high technology. Therefore, cultivation of professional logistics talent and the introduction of advanced logistics management education need to be strengthened.

The education system in colleges and universities should emphasize the commercial demands of the logistics industry. These institutes should strengthen the cooperation with enterprises and gradually form a training mode of industryuniversity research cooperation to cultivate high-quality, versatile talent for the modern logistics industry needs. Meanwhile, employees' professional capacity and ability must be improved through multilevel and multiform training, such as interviews and on-the-job training. Accordingly, a set of professional, comprehensive, and social logistics talent training systems must be constructed on an urgent basis, where preferential policies of introducing advanced talent can be formulated. Accordingly, a set of professional, comprehensive, and social logistics talent training systems must be constructed on an urgent basis, where preferential policies of introducing advanced talent can be formulated.

\section{Data Availability}

The data are taken from the online website of the World Bank and Pakistan economic survey.

\section{Conflicts of Interest}

The authors declare that there are no conflicts of interest regarding the publication of this paper.

\section{Acknowledgments}

This research was funded by the National Natural Science Foundation of China (71473013).

\section{References}

[1] R. D. Souza, M. Goh, S. Gupta, and L. Luo, “"'An investigation into the measures affecting the integration of ASEAN's priority sectors (phase 2): the case of logistics," REPSF Project, vol. 6 , no. $1,2007$.

[2] S. Bin and C. Sun, "The correlativity analysis between logistics industry and national economy development," Available at: ISSN, 2005.

[3] J.-S. Zhang and X.-Z. Hu, "Research on coupling harmony between regional logistics and regional economics," Railway Transport and Economy, vol. 34, no. 1, pp. 50-55, 2012.

[4] Y. Gao, D. Chang, T. Fang, and T. Luo, "The correlation between logistics industry and other industries: an evaluation of the empirical evidence from China," The Asian Journal of Shipping and Logistics, vol. 34, no. 1, pp. 27-32, 2018.

[5] A. Matopoulos, M. Vlachopoulou, and V. Manthou, "Exploring the impact of E-business adoption on logistics processes: empirical evidence from the food industry," International Journal of Logistics Research and Applications, vol. 10, no. 2, pp. 109-122, 2007.

[6] J. . Fras, S. Scholz, and I. Olsztynska, "Modern information technologies in the logistics of E-business," Research in Logistics and Production, vol. 7, no. 4, pp. 285-297, 2017.

[7] W. Ling, "Empirical study on relationship between foreign trade and modern logistics: based on Shanghai data from 1978 to 2008," Journal of International Trade, vol. 1, pp. 59-65, 2010.

[8] R. Puertas, L. Martí, and L. Garcia, "Logistics performance and export competitiveness: European experience," Empirica, vol. 41, no. 3, pp. 467-480, 2014.

[9] Y. Aoyama, S. Ratick, and G. Schwarz, "Organizational dynamics of the U.S. Logistics industry: an economic geography perspective*," The Professional Geographer, vol. 58, no. 3, pp. 327-340, 2006.

[10] H. H. Lean, W. Huang, and J. Hong, "Logistics and economic development: experience from China," Transport Policy, vol. 32, pp. 96-104, 2014.

[11] X. Li, K. M. Alam, and S. Wang, "Trend analysis of Pakistan railways based on industry life cycle theory," Journal of Advanced Transportation, vol. 2018, Article ID 2670346, 10 pages, 2018.

[12] S. Saidi, V. Mani, H. Mefteh, M. Shahbaz, and P. Akhtar, "Dynamic linkages between transport, logistics, foreign direct investment, and economic growth: empirical evidence from developing countries," Transportation Research Part A: Policy and Practice, vol. 141, pp. 277-293, 2020.

[13] C.-N. Wang, D. Jen-Der, and N. Thi-Kim-Lien, "Applying EBM model and grey forecasting to assess efficiency of thirdparty logistics providers," Journal of Advanced Transportation, vol. 2018, Article ID 1212873, 13 pages, 2018.

[14] H. Wang, J. Han, M. Su, S. Wan, and Z. Zhang, "The relationship between freight transport and economic development: a case study of China," Research in Transportation Economics, Article ID 100885, 2020.

[15] M. D. Sharapiyeva, A. Antoni, and R. Yessenzhigitova, "The impact of port transport-logistics infrastructure and lpi for economic growth: on the example of landlocked countries," Pomorstvo, vol. 33, no. 1, pp. 63-75, 2019. 
[16] R. Gopal, Overview of Port Logistics Infrastruc-Ture Development in ASEAN, 10th ASEAN Shipping and Ports, Jakarta, Indonesia, 2012.

[17] B. Rokicki and M. Stepniak, "Major transport infrastructure investment and regional economic development - an accessibility-based approach," Journal of Transport Geography, vol. 72, pp. 36-49, 2018.

[18] A. D’Ariano, F. Corman, T. Fujiyama, L. Meng, and P. Pellegrini, "Simulation and optimization for railway operations management," Journal of Advanced Transportation, vol. 2018, Article ID 4896748, 3 pages, 2018.

[19] S. Kuzu and E. Onder, "Research into the long-run relationship between logistics development and economic growth in Turkey," Journal of Logistics Management, vol. 3, no. 1, pp. 11-16, 2014.

[20] Y. Mishenin, I. Koblianska, V. Medvid, and Y. Maistrenko, "Sustainable regional development policy formation: role of industrial ecology and logistics," Entrepreneurship and Sustainability Issues, vol. 6, no. 1, pp. 329-341, 2018.

[21] N. M. Rashid, F. Ngalawa, and I. Cil, "Comparative study of logistic industry of Tanzania and Turkey," International Journal of Operations and Logistics Management, vol. 5, no. 2, pp. 74-82, 2016.

[22] M. Reza, "The relationship between logistics and economic development in Indonesia: analysis of time series data," Jurnal Teknik Industri, vol. 15, no. 2, pp. 119-124, 2013.

[23] A. Vulevic, “"Linkage between regional accessibillity, economic development, and logistic infrastructure," Intelligent Transportation And Planning, pp. 719-744, 2018.

[24] C. Xie and D. Luo, "Empirical studies on the relationship between logistics development and the economic growth of tertiary industry of hunan," Management and Engineering, vol. 20, p. 75, 2015.

[25] V. Navickas, L. Sujeta, and S. Vojtovich, "Logistics systems as a factor of country's competitiveness," Economics and Management, vol. 16, no. 1, pp. 231-237, 2011.

[26] World Bank, World Development Indicators, https://data. worldbank.org/country/pakistan, 2020.

[27] N. Liu and Y. Li, "Interaction between logistics development and economic growth in China," Journal of Industrial Engineering Management, vol. 21, pp. 151-154, 2007.

[28] T. Tang and C. Zou, A Study on Hunan Province Expressway and Economic Development, 2007.

[29] T. Padmore and H. Gibson, "Modelling systems of innovation:," Research Policy, vol. 26, no. 6, pp. 625-641, 1998.

[30] Yu. Chen, "Empirical analysis on the effects of logistics industry on economic growth in Jiangsu province," in Proceedings of the 2011 IEEE 18th International Conference on Industrial Engineering and Engineering Management, pp. 1454-1457, IEEE, Changchun, China, September 2011.

[31] H. Ham, T. J. Kim, and D. Boyce, "Assessment of economic impacts from unexpected events with an interregional commodity flow and multimodal transportation network model," Transportation Research Part A: Policy and Practice, vol. 39, no. 10, pp. 849-860, 2005.

[32] H. Huang and T. Xu, "Discussing about the relationship between logistics lndustry and economy derelopment," Logistics Management, vol. 5, no. 2, 2005.

[33] S. Yang and J. Zheng, "“Research on the effects of logistics industry on economic growth in jilin province in China/ RECHERCHE SUR LES EFFETS DE L'INDUSTRIE DE LA LOGISTIQUE CONCERNANT LA CROISSANCE ECONOMIQUE DE LA PROVINCE DE JILIN EN CHINE," Canadian Social Science, vol. 7, no. 6, p. 134, 2011.
[34] J.-H. Li and X. Xiong, "Analysis of spreading effects result from modern logistics industry in Guangdong province," Logistics Management, vol. 4, 2005.

[35] J. Ruan and Z. Zhen-yuan, "Input-output analysis of modern material flow industry development in Fujian province," Statistics and Information Forum, vol. 3, 2006.

[36] Z. Song and D.-L. Chang, "A study on spread effect of logistics industry in China," Journal of Business Economics, vol. 1, 2008.

[37] Z. Zhu, "Analysis of spreading effects result from logistics industry in the central plains," Science and TechnologyManagement Research, vol. 6, p. 13, 2008.

[38] W. Liu, W. Li, and W. Huang, "Analysis of the dynamic relation between logistics development and GDP growth in China," in 2006 IEEE International Conference on Service Operations and Logistics, and Informatics, pp. 153-157, IEEE, 2006.

[39] S. Y. Bo, "Empirical analysis of beijing logistics industry's GDP contribution to the national economy," in Proceedings of the 2009 First International Workshop on Database Technology and Applications, pp. 53-56, IEEE, Hubei, Wuhan, China, April 2009.

[40] D. Rondinelli and M. Berry, "Multimodal transportation, logistics, and the environment: managing interactions in a global economy," European Management Journal, vol. 18, no. 4, pp. 398-410, 2000.

[41] K. X. Li, M. Jin, G. Qi, W. Shi, and A. K. Y. Ng, "Logistics as a driving force for development under the Belt and Road Initiative - the Chinese model for developing countries," Transport Reviews, vol. 38, no. 4, pp. 457-478, 2018.

[42] W. Talley, "Linkages between transportation infrastructure investment and economic production," Logistics and Transportation Review, vol. 32, no. 1, p. 145, 1996.

[43] A. Wang, "Empirical study on the interaction relationship of regional logistics and regional economic growth," vol. 2, pp. 603-606, in Proceedings of the 2011 International Conference on Business Management and Electronic Information, vol. 2, pp. 603-606, IEEE, Guangzhao, China, May 2011.

[44] Y. T. Mohmand, A. Wang, and A. Saeed, "The impact of transportation infrastructure on economic growth: empirical evidence from Pakistan," Transportation Letters, vol. 9, no. 2, pp. 63-69, 2017.

[45] S. Liu, "A research on the relationship of logistics industry development and economic growth of China," International Business Research, vol. 2, no. 3, pp. 197-200, 2009.

[46] D. Held and A. G. Mcgrew, D. J. Perraton, Global Transformation: Politics, Economics and Culture, Polity Press and Blackwell Publishers, New York, NY, USA, 2000.

[47] W.-J. Zhang, The Relationship between the Regional Economic Growth and Logistics, , pp. 5-7, Logistics Technology, 2002.

[48] M.-K. Lee and S.-H. Yoo, "The role of transportation sectors in the Korean national economy: an input-output analysis," Transportation Research Part A: Policy and Practice, vol. 93, pp. 13-22, 2016.

[49] C. F. Tang and S. Abosedra, "Logistics performance, exports, and growth: evidence from asian economies," Research in Transportation Economics, vol. 78, Article ID 100743, 2019.

[50] S. A. R. Khan, C. Jian, Y. Zhang, H. Golpira, A. Kumar, and A. Sharif, "Environmental, social and economic growth indicators spur logistics performance: from the perspective of South asian association for regional cooperation countries," Journal of Cleaner Production, vol. 214, pp. 1011-1023, 2019.

[51] N. Bose and M. E. Haque, "Causality between public investment in transport and communication and economic growth," Available at SSRN 764465, 2005. 
[52] R. Khan, A. Syed, and Y. Zhang, "Assessing the eco-environmental performance: an PLS-SEM approach with practicebased view," International Journal of Logistics Research and Applications, pp. 1-19, 2020.

[53] S. A. R. Khan, Y. Zhang, A. Kumar, E. Zavadskas, and D. Streimikiene, "Measuring the impact of renewable energy, public health expenditure, logistics, and environmental performance on sustainable economic growth," Sustainable Development, vol. 28, no. 4, pp. 833-843, 2020.

[54] S. A. R. Khan, A. Sharif, H. Golpira, and A. Kumar, "A green ideology in asian emerging economies: from environmental policy and sustainable development," Sustainable Development, vol. 27, no. 6, pp. 1063-1075, 2019.

[55] L. Edirisinghe, "The influence of logistics competence in international trade in Sri Lanka: a contemporary study," in Sri Lanka Economics Research Conference (SLERC), 2017.

[56] N. Arshed, M. S. Hassan, M. U. Khan, and A. A Uppal, "Moderating effects of logistics infrastructure development and real sector productivity: a case of Pakistan," Global Business Review, Article ID 0972150919879307, 2019.

[57] K. M. Alam, X. Li, and S. Baig, "Impact of transport cost and travel time on trade under China-Pakistan economic corridor (CPEC)," Journal of Advanced Transportation, vol. 2019, Article ID 7178507, 16 pages, 2019.

[58] M. S. Shahbaz, M. A. Soomro, N. U. K. Bhatti, Z. Soomroe, and M. Zafarullah, "The impact of supply chain capabilities on logistic efficiency for the construction projects," Civil Engineering Journal, vol. 5, no. 6, pp. 1249-1256, 2019.

[59] A. U. Rehman, A. Hakim, K. Khan, and I. U. Khan, "Role of CPEC in development of trade, transport and economy of Pakistan," Romanian Journal of Transport Infrastructure, vol. 7, no. 1, pp. 77-92, 2018.

[60] W. Bhutto, A, A. A. Bazmi, K. Qureshi, K. Harijan, S. Karim, and M. S. Ahmad, "Forecasting the consumption of gasoline in transport sector in Pakistan based on ARIMA model," Environmental Progress and Sustainable Energy, vol. 36, no. 5, pp. 1490-1497, 2017.

[61] S. A. R. Khan, Q. L. Dong, and Z. Yu, "Study of logistics and manufacturing industry integration from the perspective of Pakistan," International Journal of Engineering Research in Africa, vol. 24, pp. 172-180, 2016.

[62] B. T. McCallum, “A reconsideration of sims' evidence concerning monetarism," Economics Letters, vol. 13, no. 2-3, pp. 167-171, 1983.

[63] D. N. Gujarati, Basic Econometrics, Tata McGraw-Hill Education, NY, USA, 2009.

[64] J. M. Wooldridge, Introductory Econometrics: A Modern Approach, 5th edition, 2013.

[65] C. Guo-hui and L. Xian-sheng, "Research on the relationship between the regional logistics and economic development based on the model VAR," in Proceedings of the 2011 International Conference on Management Science and Industrial Engineering MSIE 2011, pp. 120-124, IEEE, Harbin, China, January 2011.

[66] J. Hamilton, Time Series Econometrics, Princeton U. Press, Princeton, NJ, USA, 1st edition, 1994.

[67] C. W. J. Granger, "Some properties of time series data and their use in econometric model specification," Journal of Econometrics, vol. 16, no. 1, pp. 121-130, 1981.

[68] R. F. Engle and C. W. J. Granger, "Co-integration and error correction: representation, estimation, and testing," Econometrica, vol. 55, no. 2, pp. 251-276, 1987.

[69] S. Johansen and K. Juselius, "Maximum likelihood estimation and inference on cointegration-with appucations to the demand for money," Oxford Bulletin of Economics and Statistics, vol. 52, no. 2, pp. 169-210, 1990.

[70] M. Franzese and A. Iuliano, "Correlation analysis," Encyclopedia of Bioinformatics and Computational Biology, pp. 706-721, 2019.

[71] L. J. Christiano and J. Lawrence, "Christopher A. Sims and vector autoregressions*," The Scandinavian Journal of Economics, vol. 114, no. 4, pp. 1082-1104, 2012.

[72] C. W. J. Granger, "Investigating causal relations by econometric models and cross-spectral methods," Econometrica, vol. 37, no. 3, pp. 424-438, 1969.

[73] Z. U. O. Hong, "Investigation report of hunan logistics public information platform," Logistics Sci-Tech, vol. 36, no. 2, pp. 24-27, 2013. 